\title{
Classic congenital adrenal hyperplasia due to 21-hydroxylase deficiency, simple virilizing form
}

INSERM

\section{Source}

INSERM. (1999). Orphanet: an online rare disease and orphan drug data base. Classic congenital adrenal hyperplasia due to 21-hydroxylase deficiency, simple virilizing form. ORPHA:315311

The simple virilizing form of classical congenital adrenal hyperplasia due to 21 hydroxylase deficiency (classical $21 \mathrm{OHD} \mathrm{CAH}$; see this term) is characterized by genital ambiguity and virilization of the external genitalia in females, hypocortisolism and precocious pseudopuberty without salt-wasting. 